\title{
Focus at the interface: Evidence from Romance and Bantu
}

\author{
João Costa (Universidade Nova de Lisboa) \& Nancy C. Kula (University of Essex)
}

\section{Abstract}

Word order variation in Romance and Bantu has been related to information structure portrayed in the different discourse functions of the sentential elements involved. Based on the distribution of new information focus in Romance and Bantu, this paper argues that discourse functions need not be directly encoded in syntax. The position defended here is that syntax generates all possible structures that are filtered out at the interface with the phonological component. The prosodic phrasing of these structures is what indicates focused constituents occurring in positions of prominence. The above all significance of prosody for the determination of focus is particularly illustrated in those cases both in Romance and Bantu where, for syntactic reasons, change in word order is restricted but prosodic effects still accompany focus. The proposed interface approach to focus accounts for the variation in focus strategies and the intimate relation of focus to prosody that is attested in Romance and Bantu. Crucially, the evidence from Romance and Bantu are complementary. The Romance facts provide the necessary syntactic evidence for not positing a designated focus position in the syntactic hierarchy for focus, whereas the Bantu facts show that prosodic effects may emerge in varying ways, providing evidence for not linking a single syntactic position to a given prosodic effect. The paper in this respect highlights the similarities and differences of the role of prosody in indicating focus in stress versus tone languages.

Key Words: focus, prosody, prosodic phrasing, interface, word order, tone

\section{Introduction}

This paper investigates how central the role of syntax is in explaining word order and prosodic facts related to information structure. It is argued that cross-linguistic and language internal variation across Romance and Bantu favour an interface view of these phenomena, demoting some of the explanation from the syntactic component. Rather than presenting new data, we gather empirical evidence from both Romance and Bantu, and show how the comparison between these two language groups strengthens the argument for an interface view of information structure. The paper is organized as follows:

Section 2 summarizes the debate on the role the syntactic component plays in explaining cases of word order and prosodic variation related to new information focus, and sets the goals of the paper.

In section 3, we present data from Romance showing that word order variation facts are a by-product of what syntax can generate, and that marked stress appears as a last-resort strategy whenever the syntax, for reasons independent of information structure, is not able to generate a given output.

Section 4 presents data showing the properties of focused constituents in Bantu, providing evidence that a syntactic approach fails to explain the correlation between prosody and focus, and the variation in prosody attested in focus constructions.

In section 5, we make clear how the comparison between Romance and Bantu contributes to a better understanding of the interaction between syntax, prosody and discourse.

Finally, in section 6, the main conclusions of the paper are presented. 


\section{Syntactic approaches to focus vs. Interface views}

The relation between information structure and syntax has been subject to a long debate over the last decade. It is consensual that word order variation in many languages reflects the discourse function of the elements of the sentence. An example of this so-called discourse configurationality is attested by data such as those illustrated by the variable position of the subject in European Portuguese:

\section{(1) A: O que é que o João fez? \\ 'What did João do?' \\ B: $\quad$ O João tossiu. \\ 'João coughed' \\ \#Tossiu o João. \\ 'Coughed João'}

(2) A: Quem tossiu?

'Who coughed?'

B: Tossiu o João.

'Coughed João.'

\#O João tossiu.

'João coughed.'

As shown in (1) and (2), the position of the subject appears to depend on its information status: if it yields new information, or is the focus of the sentence, it occurs postverbally; if it conveys given information, as in (1), it can be moved to the sentence-initial position, where it gets nominative case and/or checks the EPP feature. This type of word order variation is well documented for Romance languages, like European Portuguese (Costa 1996), Spanish (Zubizarreta 1998) and Italian (Belletti 2002). As discussed by most authors who have worked on this topic, the word order variation facts are not to be considered without taking into consideration the intonational properties of these contexts. Whenever the subject occurs in a low position, it bears the sentence nuclear stress, which gives it the appropriate prominence in order to be interpreted as focus. Independently of the variation in the analysis of this type of phenomena, all descriptions converge on the following generalizations:

(a) Word order variation may reflect different information structures;

(b) Information focused constituents occur at the rightward periphery where they are assigned sentence nuclear stress.

A general descriptive conclusion that can be taken from these generalizations is that any account of facts of this type must take into account syntax, prosody and information structure. The debate alluded to above has to do with different analyses of the interaction between these components in explaining these facts. In short, two main lines of enquiry have developed.

One type of approach codifies focus (and other discourse-related categories) as a syntactic primitive, instantiated as a feature (e.g. Horvath 1986) or as a functional category (e.g. Belletti 2002). Under this type of approach, the prosodic effects are either disregarded or taken as a secondary consequence of the syntactic configuration. The latter view is, for instance, endorsed by followers of Cinque's (1993) syntactic approach to sentence nuclear stress assignment. If we combine these two views, namely the codification of focus as a syntactic primitive with a syntactic algorithm for sentence stress assignment, we end up with a syntacticocentric view of this type of phenomena. 
An alternative approach to a syntactic analysis of discourse configurationality proposes that discourse notions like new-information focus are not encoded in syntax as functional categories. According to this view, defended, for instance, in Reinhart (1995), Szendroi (2001) and Costa $(1998,2004)$, the syntactic component is blind to this type of information and its role is just generating structures that may be filtered out at the interface with the phonological component. The latter will read the syntactic information and map it onto prosodic categories, as claimed in Nespor and Vogel (1986).

In order to distinguish the two types of approach, let us consider a well-known example of a syntactic operation that interacts with prosodic factors: heavy NP shift, illustrated in (3):

(3) a. *I read yesterday the book.

b. I read yesterday all the books my friend had recommended.

A view advocating the integration of prosodic information in the syntactic component might claim that the rightward movement of the DP object is driven by prosody, since the condition for it to operate is the weight and prosodic branching of the DP object (see, for instance, Frota and Vigário 2002). ${ }^{1}$ The less syntacticocentric view would claim that syntax generates shifted and non-shifted DP objects, and at PF, shifted light DPs are ruled out, because of prosodic constraints. It is not clear how empirical argumentation on the properties of Heavy NP shift enable distinguishing the two approaches, so further evidence from other domains is needed in order to make an explicit comparison between the two types of analyses.

We contend that a closer scrutiny of word order variation and prosodic realization of focus across Romance and Bantu provides the necessary empirical domain to address this issue. The goal of this paper is, therefore, to present data from Romance and Bantu showing that there is reason to believe that syntax does not necessarily encode focus as a primitive, and that the prosodic manifestation of focus is not derived in syntax. It will be argued that the different sources of evidence provided by the Romance and the Bantu facts are complementary, leading to a more robust argumentation in favour of the interface view.

\section{Focus in Romance}

\subsection{Focus as a syntactic primitive?}

As mentioned in the previous section, it is a robust fact that null-subject Romance languages allow subject-verb inversion, and that this word order is used whenever the subject is focused. Two competing analyses of inversion have been put forward in recent literature. Costa (1996) and Zubizarreta (1998), among others, propose that the inverted subject is in Spec,VP, while Belletti (2002) suggests that the low subject sits in the specifier of a low focus-related functional category. The two partial representations are given in (4): ${ }^{2}$

(4) a. $\quad[\mathrm{TP} \mathrm{V}[\mathrm{vP}$ Subj tv...

b. $\quad\left[\mathrm{TP} V\left[{ }_{\text {FocP }}\right.\right.$ Subj $\left[\mathrm{t}_{\text {subj }} \mathrm{t}_{\mathrm{V}} \ldots\right.$

Under Belletti's approach the focus interpretation of the inverted subject is accounted for straightforwardly, since the motivation for the low position is for it to occupy a designated functional projection responsible for the discourse interpretation. The Spec,VP approach does not account for the interpretation directly. Costa (2004) contends that syntax of null-subject languages may generate SV and VS orders. Whenever a VS order reaches the phonological component, the sentence is mapped onto an Intonational Phrase where the rightmost element 
is assigned the main prominence of the sentence (Frota 1998). Since focused elements must be salient, this conspiracy between syntax and prosody accounts for the focus interpretation of the subject.

At this point, it is necessary to make clear how discourse interacts with the other components. According to the view advocated here, syntax is blind to the information status of the sentence constituents. As such, the low position of the subject is not a consequence of its informational status, but rather an option made legitimate by the parameter setting of null subject languages. In a similar way, nuclear sentence stress assignment just operates assigning prominence to the rightmost constituent in the Intonation Phrase. At this stage, in a null subject language, there are two potential outputs being generated, requiring a filtering operation to apply. The proposal we are making is that discourse plays this filtering role. Discourse requirements impose that the focused constituent of a sentence be prominent. Since prominence has been assigned by sentence stress assignment, an output in which the focused constituent is in the rightmost position may be selected. As such, discourse interacts with the computational component acting as a device selecting or filtering out convergent derivations.

There are three domains in which the two types of analyses make different predictions. In order to understand how they can be compared, it is important to emphasize that encoding focus as a syntactic primitive predicts that focalization is a matter solved in the syntactic component. Accordingly, whenever a given constituent is marked as focus, it is a good candidate to move to a Focus Phrase. Consequently, it is expected that all focused subjects in languages that display this type of discourse configurationality may occupy this position. Under the Spec,VP approach, it is expected that, provided the syntactic licensing requirements for subjects in Spec, VP are met, any subject can sit in this position. However, if such requirements are not met, it will not be able to surface there, independently of its focal nature. In other words, the main difference between the two approaches lies on the relevance of focus for determining the position of the subject in the syntactic component.

\subsection{Subject-verb inversion crosslinguistically}

In Costa and Figueiredo Silva (2006), it is shown, following many authors, that European and Brazilian Portuguese do not differ significantly as far as discourse-configurationality is concerned. The two varieties of Portuguese display a wide array of constructions for which discourse notions such as topic and focus are relevant (e.g. VP-ellipsis, null objects, topicalization). Importantly, the general Romance tendency to place focused constituents at the right periphery is observed in Brazilian Portuguese, and is attested, for instance, in the order of complements of ditransitive verbs, as illustrated in (5-8) (from Costa and Figueiredo Silva 2006):

(5) Brazilian Portuguese:

A: O que o João deu pra Maria?

'What (did) João give to Maria?'

B: $\quad$ O João deu pra Maria um CD.

'João gave Maria a CD'

(6) Brazilian Portuguese:

A: Pra quem o João deu o CD?

'To whom (did) João give the CD'

B: $\quad$ O João deu o CD pra Maria.

'João gave the CD to Maria' 
(7) European Portuguese:
A: O que é que o João deu à Maria?
'What (did) João give to Maria?'
B: $\quad$ O João deu à Maria um CD.
'João gave Maria a CD'

(8) European Portuguese:
A: A quem é que o Јо̃̃o deи o CD?
'To whom (did) João give the CD?'
B: $\quad$ O João deu o CD à Maria.
'João gave the CD to Maria'

Since these data show that Brazilian Portuguese displays the regular tendency for aligning focused constituents with the right periphery, and since, according to Belletti (2002), focus at the right periphery emerges because of the availability of the low Focus Phrase, it is legitimate to suppose that Brazilian Portuguese also has a low Focus Phrase in its inventory of functional categories.

However, a problem arises when the behaviour of focused subjects with transitive and intransitive verbs is compared in these two languages. As shown in (9), in Brazilian Portuguese, unlike what we described above for European Portuguese, focused subjects do not invert. Instead, they occur preverbally and bear a marked stress:

(9) A: Quem comeu o bolo?

'Who ate the cake?'

B: a. Comeи o João. (EP/*BP) 'ate João'

a'. O JOÃO comeu. (\#EP/BP)

'João ate'

Since it cannot be claimed that Brazilian Portuguese is not a discourse configurational language, there are no grounds on which to say that the difference between the two languages derives from some macro-parametric difference on the relation between word order and discourse. There is also no reasonable explanation to consider that the low FocP is not projected only when the subject of a specific subclass of verbs is involved.

Let us then turn to see how the view that does not encode focus as a syntactic primitive handles this set of data. Recall that, according to this view, a subject can be inverted for purely morpho-syntactic reasons. Its focus interpretation derives from the assignment of prosodic prominence at the interface with PF. Under this view, thus, what triggers the low position for the subject is not its informational status, and this is the crucial difference. A well-known difference between European and Brazilian Portuguese is that the latter is loosing null subjects and some of the constructions related to this property (see Duarte 1995, Figueiredo Silva 1996, among others). One of the constructions related to the null subject property that has been lost is subject-verb inversion. This explains, on syntactic grounds, that the subject is not able to sit in a low position, which is completely independent of its informational status. In accordance to the type of analysis argued for above, the syntax of Brazilian Portuguese, unlike what happens in European Portuguese, is not able to generate a VS order. So, the only legitimate syntactic output that can be sent to PF is an SV order. The SV sentence is mapped onto an Intonational Phrase, but the prominence at the right periphery will not be in accordance with discourse requirements. A marked stress is then used as a lastresort strategy, as defended in Reinhart $(1995,1999) .^{3}$ 
As suggested in Costa and Figueiredo Silva (2006), this context is a good testing ground for comparing the two approaches to focus and inversion. The one claiming that focus is a syntactic primitive does not provide a clear explanation for the language internal and cross-linguistic variation just presented, because it predicts that all focused constituents will be able to surface at the designated functional category that is responsible for their interpretation.

\section{3. (Focus-)Inversion is sensitive to locality}

A further argument in favour of the interface view comes from cases in which a focused subject is found inverted under an infinitival form, as described in Costa (2004). It is proposed that null subject languages allow inversion because subject case licensing can be established under Move or Agree (Chomsky 2001), as illustrated in (10):

(10) a. [IP $S_{\text {[CASE] }} I_{[\text {CASE] }}\left[{ }_{\mathrm{vP}} \mathrm{t} \mathrm{t}\right.$

b. [IP $\mathrm{I}_{[\mathrm{CASE}]}\left[\mathrm{vP} \mathrm{S}_{\text {[CASE] }} \mathrm{t}\right.$

Evidence for licensing under agree comes from the fact, illustrated under (11), that a phase boundary forbids the licensing of inversion:

(11) a. Querem ler todos os alunos esse livro. Want-3pl read all the students that book

b. *Recusaram ler todos os alunos esse livro. Refused-3pl read all the students that book

c. TODOS OS ALUNOS recusaram ler esse livro. All the students refused to read that book

d. *Negaram ler todos os alunos esse livro. Denied to read all the students that book

e. TODOS OS ALUNOS negaram ler esse livro. All the students denied to read that book

Costa (2004) shows, based on transparency effects, that the difference between querer "want", and recusar "refuse" or negar "deny" is that the latter two project an embedded CP, blocking the Agree relation between the matrix verb and the embedded subject.

The relevance of this set of data for the debate is the following: if the condition for a subject to appear in a low position would be its information status, and the requirement that it appear in a focus projection, where it is assigned a specific interpretation, such a position should be available in the embedded domain, independently of there being a CP boundary between the matrix and the embedded position. Moreover, the existence of such a boundary does not preclude focus assignment, as shown in (11c) and (11e). Instead, the focus subject is marked as focus with a heavy stress, in a way reminiscent of what was observed for Brazilian Portuguese. Alternatively, if the low embedded position is just a position where the subject can be licensed under Agree by the matrix $\mathrm{T}$ head, it follows that this type of licensing is sensitive to a phase boundary. Such sensitivity crucially depends on purely syntactic matters, and the focus interpretation for the embedded subject is an independent matter. Summing up, this specific context reinforces the idea defended above for the comparison between European and Brazilian Portuguese that discourse configurationality is parasitic on the independent availability of a given syntactic configuration. Accordingly, the encoding of focus is not a purely syntactic matter. 
This case also presents evidence for the last resort strategy for marking focus with heavy stress, in line with Reinhart's (1995) proposal, which was shown to work under the view that sentences are mapped onto intonational phrases, with assignment of default prominence and, if necessary, further repair.

\subsection{Possessives in Portuguese and Italian}

In Cardinalletti (1998), it is shown that pre-nominal and post-nominal possessives are XPs in Italian, and that post-nominal possessives are used in definite contexts, only if they are focused. Data in (12) are drawn from Cardinaletti (1998: 19-20).

(12) a. *la SUA casa, non tua the her house, not yours

b. la casa SUA, non tua the house hers, not yours 'Her house, not yours'

These data are interesting, since they confirm, in the nominal domain, the general Romance tendency to place focused constituents at the right periphery. Comparing the possessive system of Italian with that of European Portuguese, Miguel (2001) and Castro and Costa (2003) provide evidence, based on modification, prosodic reduction and coordination facts, to argue that Portuguese pre-nominal possessives are heads. Assuming these results, we obtain a categorial difference between pre-nominal possessives in the two languages: in Italian, they are XPs, while in European Portuguese, they are heads.

Focalization of the possessive is one of the areas in which the two languages diverge. Unlike in Italian, in European Portuguese, a focalized possessive is not post-nominal (Castro and Costa 2003). Instead, it bears heavy stress.

(13) a. Esse é o MEU problema, não o teu. that is the MY problem, not the yours

b. *Esse é o problema meu, não o teu. that is the problem my 'That is MY problem, not yours'

This is similar to what is found in focalization involving heads in the sentence. When we compare the behaviour of arguments and adjuncts with the behaviour of verbs in the Romance languages, it is possible to observe that XPs (arguments and adjuncts) may display different positions, reflecting different information structures, while $\mathrm{X}^{\mathrm{o}} \mathrm{s}$, like verbs, have a much more rigid distribution. In line with what we proposed above, this follows from syntactic constraints: XPs may be licensed in several positions, depending on the language at stake, as was exemplified with the two positions for licensing subjects in European Portuguese, while $\mathrm{X}^{\mathrm{o}}$ movement is categorical, occurring across-the-board. For example, if a language has $\mathrm{V}$-to-T movement, the verb always moves to $\mathrm{T}$, and there is no case in which it is licensed in-situ.

Bearing this difference between $\mathrm{X}^{\mathrm{o}} \mathrm{s}$ and XPs in mind, we can understand the different focus strategies used for possessives in European Portuguese and in Italian. The difference follows from the categorial status of possessives in the two languages. Assuming that prenominal possessives are heads in Portuguese, they do not enter into configurations typical of XPs, which permit the post-nominal order. In Italian, because of their XP-status, possessives may surface in two different configurations. 
This case is interesting, since it reveals that the position of the possessive and its relation with its discourse function solely derives from its categorial status. Notice that it cannot obviously be argued that Portuguese does not resort to word order strategies for encoding focused constituents. This is just not an available option for heads, since they are licensed in the syntax in a more categorical way.

If focus were encoded directly into the syntactic structure of the DP, as proposed for instance by Roca (2006), we would expect possessives to surface in a similar position (with a possible variation between specifier and head position) independently of their categorial status.

\subsection{Partial conclusion}

The data discussed in this section provide evidence for not encoding focus directly in syntax, but for a more articulated theory of focus in which the legitimate outputs of syntax are mapped onto the prosodic and discourse components. The facts described also enable a better understanding of the distribution of focus in Romance, departing from a simplistic view according to which one would say that this discourse function is marked by word order alone.

It could nevertheless still be argued that an alternative view provides evidence for treating the tendency for focus to appear rightmost as a consequence of a direct encoding of discourse into the computational component. Cinque (1993) proposes that sentence nuclear stress is assigned within syntax to the most embedded constituent. If a constituent is marked as focus in syntax, it must stay in the position where it receives sentence stress. According to this view, syntax is capable of accounting for the position, the interpretation, and the stress of focused constituents.

The evidence to be presented from Bantu languages in the next section, where no notion of sentence stress can be upheld, will help to clarify this matter and dismiss this alternative proposal.

\section{Focus in Bantu}

Focused constituents can occur in in-situ, post-verbal, initial and final positions in Bantu, depending on the language (see Marten 2007 for a review of focus positions in Bantu). In addition, cleft constructions are an alternative way of marking focus that is used by all Bantu languages. As has been shown for Romance, Bantu languages also provide negative evidence for treating focus as encoded in syntax. We will look at two issues in this respect. Focus in the so-called immediate after verb position (IAV) as established by Watters (1979) where focus involves change in word order, and in-situ focus where no change in word order is seen but rather, prosodic phrasing identifies focused constituents.

In contrast to the Romance data discussed above, the Bantu data will make no reference to the notion of sentential stress and accompanying nuclear stress rules as the cases investigated in detail involve tone languages where stress plays no role. The idea of prominence is therefore also, pending further investigation of Bantu intonation, not to be understood in the classical sense but can only be assumed in as far as we assume focus constituents are in some sense prominent in relation to the other non-focused constituents in a sentence. ${ }^{4}$ It will be shown that focus is best analysed as indicated by prosodic phrasing with the focus of a sentence occupying the right-edge of a prosodic phrase, at least for the cases at hand.

Like Romance languages, Bantu languages have also been argued, on the basis of data such as (14) from Chichewa (Bresnan and Mchombo 1987) - that can be replicated in many 
other Bantu languages - to be at least partially discourse configurational (see for example Baker 2003, Morimoto 2000). ${ }^{5}$

(14) Chichewa
a. Njûchi zi-ná-wá-lum-a a-lenje (SVO)
10.bees SM10-PAST-OM2-bite-FV 2-hunters
'The bees bit the hunters'
b. Zináwáluma alenje njûchi
(VOS)
c. Alenje zináwáluma njûchi
d. Zináwáluma njûchi alenje
e. Njûchi alenje zináwáluma
f. Alenje njûchi zináwáluma
(OSV)

Although these data are discussed in relation to the distribution of object and subject clitics in Bresnan and Mchombo (1987), namely that the different word orders for the same expression in (14) are licensed by the presence of pronominal clitics on the verb, the different word orders are also generally understood to involve information structure and the licensing of different discourse functions (Marten 2007). If such variation in word order is licensed by the syntax of Bantu and accompanied by discourse functions then it could be argued that a Focus Phrase which satisfies the discourse functions of focus constituents also exists and attracts focus to occur in the head of this functional projection. Data showing focus in an immediate after verb position, which we discuss in the next section, could be such a case.

\subsection{Focus in immediate after verb (IAV) position}

Since Watters (1979) and Hyman and Watters (1984) the Bantu literature has made reference to an IAV position in some Bantu languages. The data on which this position is based is owed to the Western Grassfields Bantu language Aghem where constituents in focus consistently appear in the position immediately following the verb as the data in (15) show. Aghem and all Bantu examples to follow have canonical SVO word order.

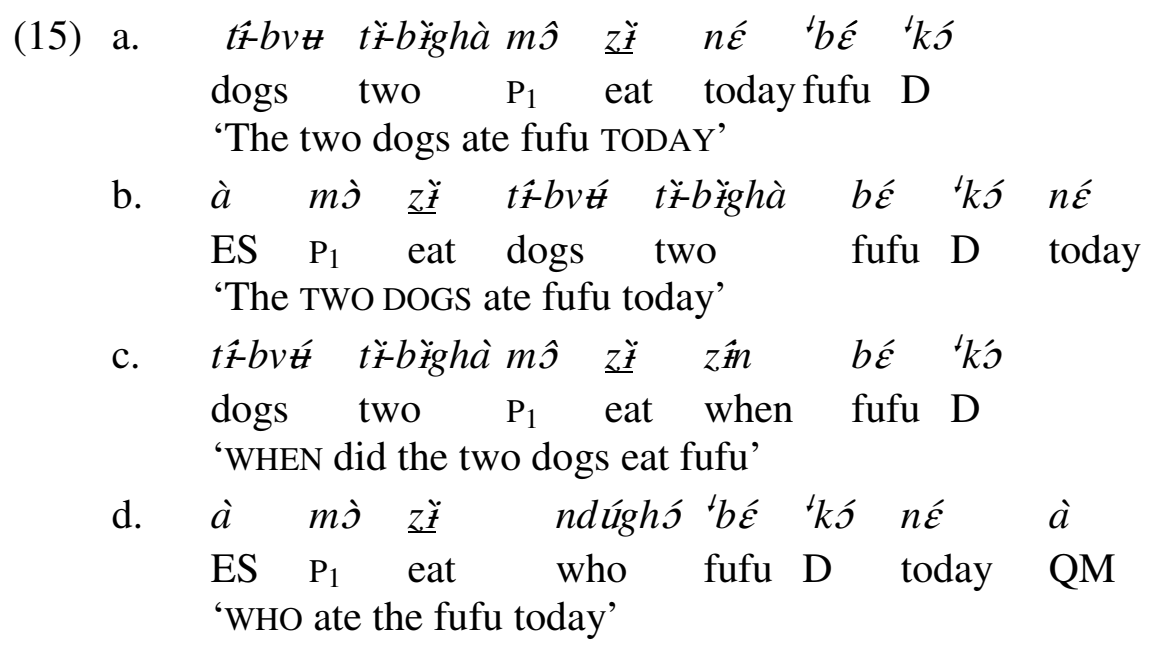

In (15a) we see that the adverb appears in the IAV position under focus, as does the subject in $(15 b)$, as well as the $w h$-words in $(15 c-d)$. Based on these and similar facts in other Bantu languages a number of analyses including Sabel and Zeller (2006), Aboh (2007), Ndayiragidje (1999) and van der Wal (2006), have argued for a low focus position along the lines of Belletti (2002). The idea is that a low FocP projection is available between the 
inflectional domain and the verb and focused constituents get their focal interpretation by moving to the specifier of this position. We would like to challenge this position, at least for a sub-set of Bantu languages for which it has also been argued that an IAV position exists. Specifically, we would like to argue that there is no FocP or structurally defined position for the IAV in syntax but rather that what turns out to be IAV focus stems from a subset of interrelated factors in particular the so-called conjoint-disjoint distinction and prosodic phrasing.

Before we come to this, however, let us first review some of the facts that may be considered amenable to an IAV focus position analysis. In both Makhuwa (van der Wal 2006) and Bemba there is reason to consider an IAV position as available in these languages. Consider the data from Makhuwa (van der Wal 2006: 239-241) where the focused constituent is in the IAV position in (16). And the Bemba case in (17) where it seems as though the focused constituent moves to the IAV position.

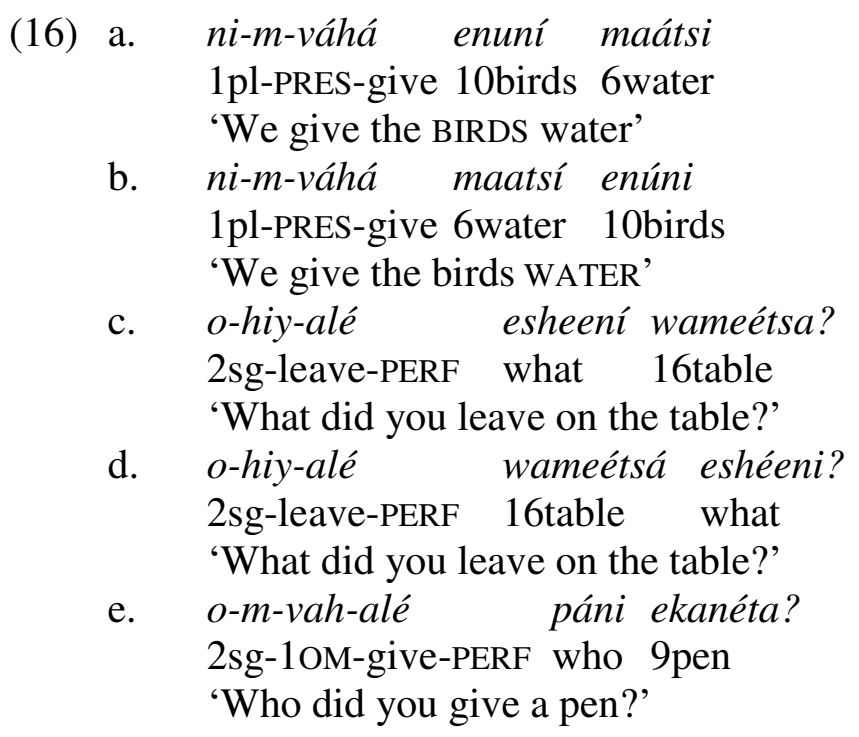

In (16a) the canonical order between direct and indirect object contrasts with (16b) where the focused direct object occurs prior to the indirect object in the IAV position. (16c\&e) are constituent $w h$-questions where the $w h$-words occur in the IAV position in contrast to in-situ. Note though that (16d) with the wh-word in-situ is also possible although it is less preferred. On the surface then, it seems that Makhuwa can focus constituents in the IAV position.

Consider further the case of Bemba in (17) where the same sentence can attest different word orders where the constituent in IAV (convincingly in 17d-e) is in focus.

(17) Bemba
a. tù-kà-byáálà inyànjé mwíbala màílò (broad/VP focus) 1PLSM-FUT-plant 9maize 16garden tomorrow
'We will plant maize in the garden tomorrow'
b. tùkàbyáálá ínyànjé mwíibàlà màílò
(verb focus)
'We will plant maize in the garden tomorrow'
c. tùkàbyáálà ínyànjè mwíibàlà màílò
'We will plant maize in the garden tomorrow'
d. tùkàbyáálà mwííbàlà ínyànjé màílò
'We will plant maize in the garden tomorrow'
e. tùkàbyáálà màílò ínyjànjé mwíbàlà
'We will plant maize in the garden tomorrow'
(object NP focus)
(locative focus)
(adverbial focus) 
(17a) presents the canonical order of the sentence and also broad VP focus. (17b) indicates verb focus despite having constituents following the verb, an issue to do with the difference in tone on the verb in contrast to the other examples. We return to this presently. (17c) shows an object focused in IAV but is not conclusive as this would also be its canonical position. In contrast (17d-e) show that the locative and the adverb appear in the IAV position to induce different scopes of focus for the same sentence.

Based on the data in (16-17) it seems as though the low focus-related functional category may be a viable option. However, closer examination of the distribution of focus in these languages warrants a different perspective. An important fact about the data in (16-17) is that focus in IAV is intertwined with the so-called conjoint-disjoint distinction. The conjoint-disjoint distinction - an observation owed to Meeussen (1959) for Kirundi - is a distinction found mainly in verb forms of particular tenses that indicates whether a verb is final in its clause or not. Although this distinction is generally found in verbs it has also been argued to be attested in nouns (see Sharman \& Meeusen 1955, Kula 2007). The following are the oft-cited examples from Creissels (1996) from Tswana.

(18) Conjoint-disjoint in Tswana

\begin{tabular}{|c|c|c|c|}
\hline a. & $\begin{array}{l}\text { kè tlàà bíná lí } \\
\text { ISG. TNS dance and } \\
\text { 'I too dance/am dancing' }\end{array}$ & $\begin{array}{l}\text { nná } \\
1 \mathrm{SG} .\end{array}$ & DISJOINT (DJ) \\
\hline b. & $\begin{array}{l}\text { kè tlàà bínà lé } \\
\text { ISG. TNS dance and } \\
\text { 'I am dancing with him' }\end{array}$ & $\begin{array}{l}\text { èné } \\
1 \mathrm{SG} .\end{array}$ & CONJOINT $(\mathrm{CJ})$ \\
\hline c. & $\begin{array}{lll}k \grave{e} & \grave{a} & \text { mó-rátà } \\
\text { SM1SG. } & \text { DISJ } & \text { OM1-like } \\
\text { 'I like him' } & \end{array}$ & & DJ \\
\hline d. & $\begin{array}{lll}\text { ké ràtà } & \text { Mphó } \\
\text { SM1SG like } & \text { M. } \\
\text { 'I like Mphó' } & \end{array}$ & & $\mathrm{CJ}$ \\
\hline e. & $\begin{array}{l}\text { kè à mó-rátà Mphó } \\
\text { 'I like him, Mphó' }\end{array}$ & & DJ \\
\hline
\end{tabular}

The conjoint-disjoint distinction can either have a segmental morpheme marker as in (18c-e) or be purely tonal as in (18a-b). Creissels' (1996) observation of the distinction is that when the disjoint form of the verb is used, the verb is final in its clause, any following information is discourse old. In contrast, conjoint verb forms indicate that the verb is not final and there is following, new information. In (18a) the disjoint form of the verb is marked by two high tones on the verb while in (18b) the conjoint form is marked by the high-low tone pattern of the verb. In this case the verb cannot be final and new information given by him must follow the verb. In examples (18c-d) the distinction is marked by the presence of the low toned morpheme $-\grave{a}$ - in the disjoint form (18c) while its absence indicates the conjoint form in (18d). (18c) presupposes that the person to whom the pronoun him refers has already been introduced in the discourse so that its use here signals old information, hence the use of the disjoint form. In contrast, use of the proper name Mpho in (18d) signals that it is discourse new and the conjoint form of the verb must be used. If Mpho occurs as an afterthought topic, the disjoint form of the verb must be used as shown in (18e).

Note that while the description of the conjoint-disjoint distinction as observed by Meeussen (1959) as indicating whether a verb is final or not in its clause is uncontentious, the direct relation of focus to the distinction rather is. Thus, Buell $(2005,2006)$ argues against such a direct relation showing that in Zulu conjoint forms can also be found with presupposed 
information such as resumptives. Consider the Zulu data in (19a-b) where the disjoint form is indicated by the presence of the morpheme $y a$ - and the conjoint form by its absence. In these cases (19a-b) the focus facts are the expected but (19c) on the other hand, where the conjoint form is used with a following resumptive pronoun, poses a problem.

(19) Zulu

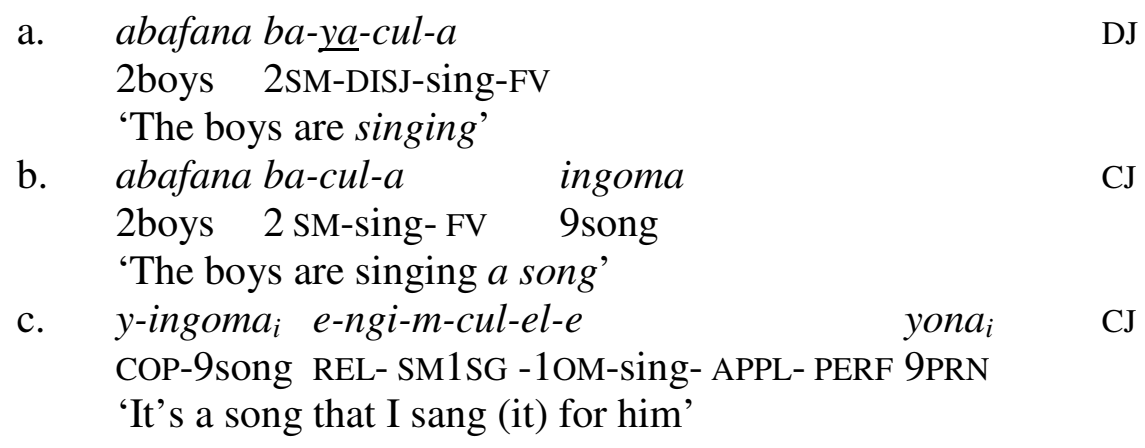

In (19c) the direct object is doubled with the resumptive independent pronoun yona but the conjoint form of the verb is still used. This is unexpected if the conjoint form directly encodes a following constituent as focused. ${ }^{6}$ Based on this and other cases where sentences with neutral focus also use the conjoint form, Buell (2006) rejects an analysis that directly links the conjoint-disjoint distinction to focus, at least for Zulu, although a weak correlation may be made in that no constituent following a disjoint form can be in focus. He rather proposes that the distinction is sensitive to constituency, in particular AgrSP, and solely indicates whether a verb form is final or not within this constituent. Any focal interpretations are treated as the by-product of a range of interpretations available to non-topicalised elements. Further in Buell (2007) he argues that focus is essentially in-situ and adheres to focus induced extraposition where no other elements may appear in the VP when a focused element also occurs there. We return to these issues presently but we are basically in keeping with this analysis but veering towards prosody as the indicator of this 'extraposition'. Note though that, interestingly, Zulu presents a slight reversal of the facts as attested so far as although constituents in IAV are not systematically focused after a conjoint verb form, constituents in IAV are systematically not focused with disjoint forms. ${ }^{7}$

For both the Bemba and Makhuwa data presented IAV focus only occurs in conjoint forms. And even in these cases in-situ focus, as already seen in the Makhuwa constituent question example in (16d), is marginally acceptable. Furthermore, in the Bemba case we have investigated and present here, the conjoint-disjoint distinction interacts with prosodic phrasing so that disjoint forms have a phonological phrase boundary following the verb while conjoint forms do not. To highlight the role of prosody in these cases we will only concentrate on cases where the conjoint-disjoint is tonally marked or accompanied by specific prosodic effects.

As we have also argued for Romance above we contend with the idea that the different word orders attested in the cases of IAV focus is not a result of movement to a focus position but is rather owing to a free and blind generation of syntax, concurring with the well established fact of relatively free word order in Bantu (cf. Bresnan and Mchombo 1987). The different word orders are then mapped onto a prosodic phonology whose prosodic phrasing is aided by the (tonally marked) conjoint-disjoint distinction. We thus are in agreement with Hyman (1999) who shows that tone can only be indirectly related to focus. We further, given the observations of Buell (2006), do not want to directly encode focus as induced by the conjoint-disjoint distinction per-se but rather argue that the conjoint-disjoint distinction, particularly when it is tonally marked, provides cues for prosodic phrasing that help to assign 
a focused constituent within or at a phonological phrase edge. This implies that other factors may influence prosodic phrasing choices and the conjoint-disjoint distinction is only one of these. What is crucial then is that prosodic phrasing provides enough information to identify focus constituents as falling - in this instance - at the right edge of a phonological phrase. We now look in more detail at the relation between conjoint forms and prosodic phrasing, on the one hand, and focus, on the other.

\subsubsection{Conjoint-disjoint forms and focus}

Within the Bantu languages, there is a disparity in IAV focus between languages with the conjoint-disjoint distinction and those without it. One explanation for this distinction on the verb is that it provides information for the hearer on whether a following constituent is salient for the interpretation of the foregoing discourse. Thus, as already pointed out, conjoint tone is indicative of new information while constituents following disjoint tone are discourse old. ${ }^{8}$ This is further illustrated by the impossibility of having conjoint tone when an object concord/pronoun is incorporated in the verb form. ${ }^{9}$

(20) Bemba

$\begin{array}{lll}\text { a. } & \text { tu-álée-lóndól-a Mutale } & \text { CJ } \\ & \text { SM1PL-P4PROG-find-FV Mutale } \\ & \text { 'We found Mutale' } & \\ \text { b. } & \begin{array}{l}\text { tu-áléé-mú-lóndól-á } \quad \text { Mutale } \\ \text { SM1PL-P4 PROG-1OM-find-FV Mutale }\end{array} & \text { DJ } \\ & \text { 'We found him Mutale' } & \\ \text { c. * } & \begin{array}{l}\text { tu-áléé-mú-lóndól-a } \\ \text { SM1PL-P4PROG-1OM-find-FV Mutale }\end{array} & \text { CJ } \\ & \text { 'We found him Mutale' }\end{array}$

As seen in (20c) the use of conjoint tone with the object marker $m u$ - makes the sentence ungrammatical because the object NP Mutale is discourse old; disjoint tone must be used instead (20b). This is in contrast to (20a) where the object marker is absent and Mutale is new information; the conjoint tone is used.

Having a closer look at the data in (16-17) we notice that they portray this conjointdisjoint distinction. In Bemba, disjoint forms are indicated by having high tone run through the verb form to the final syllable, while no such tone spread in seen in disjoint forms. Thus, in (17b) where the verb is in focus and hence final in its clause disjoint tone is seen on the verb form indicating that following constituents fall outside the verb's clause. In contrast to this, conjoint tone is seen in $(17 \mathrm{c}-\mathrm{e})$ where the following constituent is incorporated into the verbs clause and is hence focused. In Makhuwa (16), on the other hand, the morphological marking (indicated on disjoint forms) of the distinction goes alongside a tonal distinction on the constituent following the conjoint form. A process of tonal lowering is applied to the focused constituent as shown in the differing tone pattern of maátsi 'water' as LHL when it is not in focus but LLH when it is and preceded by a conjoint verb form. In both cases, there is a strong co-relation between focused constituents and the conjoint form of the verb even though the marking of the conjoint and disjoint forms is language specific.

The presence of the conjoint-disjoint distinction is attested to varying degrees in different Bantu languages. ${ }^{10}$ An interesting fact with respect to IAV focus is that those languages that lack the conjoint-disjoint distinction generally do not exhibit IAV focus and if they do, it tends to be accompanied with definitive prosodic effects. Consider in this respect Swahili and Tumbuka, which have no conjoint-disjoint distinction. In Swahili, which is non- 
tonal, focus is final and no IAV focus is seen as the examples in (21) (Ashton 1942, Krifka 1985) show.

(21) Swahili
a. zi-jaz-e ma-ji ndoo
10OM-fill-SUBJ 6water 10bucket
'Fill the buckets (not the tin cans) with water'
* 'Fill the buckets with the water'
b. zi-jaz-e ndoo maji
10OM-fill-SUBJ 10bucket 6water
'Fill the buckets with water (not milk)'
* 'Fill the buckets with water'

In Tumbuka (Downing 2006) on the other hand, focus can be either initial (not a cleft) as in $(22 \mathrm{a}-\mathrm{b})$ or can be in the IAV position (22c-d). In both cases however, prosodic effects are seen, namely; prosodic boundary narrowing creating a phonological phrase boundary after the focused constituent. In addition to this, a constituent following the focus is noticeably downstepped (indicated by !) in the IAV case. Data in (22) are presented with parenthesis indicating phonological phrasing.

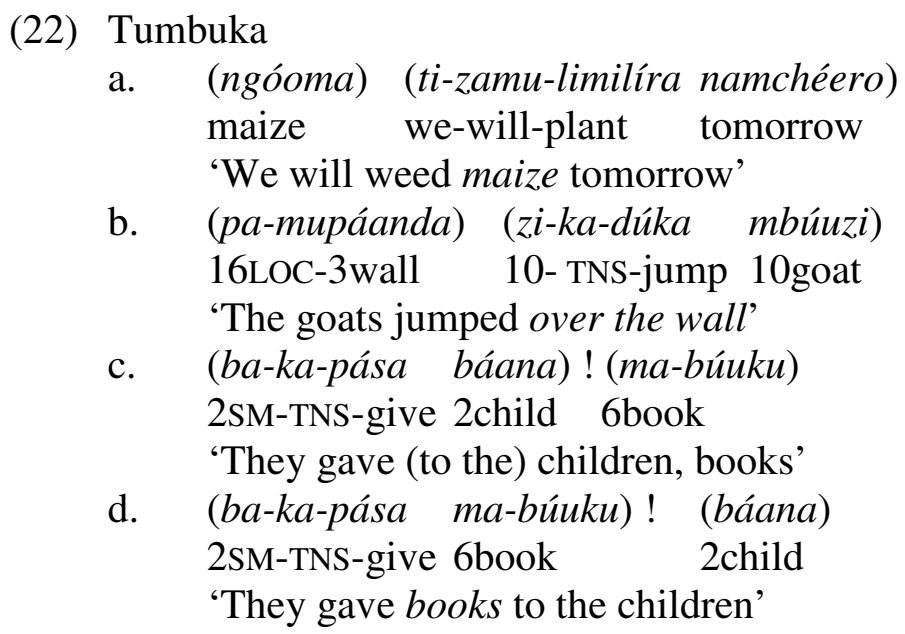

The cue for phonological phrase boundaries in Tumbuka (as in a number of other Bantu languages) is penultimate lengthening. Thus, in (22a-b) the penult of the focused constituent is lengthened, indicating that a phonological phrase boundary must immediately follow. The same effect is seen for focus in the IAV position in addition to which the following constituent is downstepped, i.e. high tone on this constituent is produced at a lower pitch. We therefore see that in the absence of the conjoint-disjoint distinction in Tumbuka some other prosodic effect is at work to indicate IAV focus. ${ }^{11}$

The variable occurrence of focus in final and initial focus in (21-22) and also possibly in-situ focus in Tumbuka, are not expected under a focal functional projection analysis. The prediction in this case would be that every focus occurs in the same position, at least in the same language. Indeed, analyses that try to maintain such a position have been proposed involving a focal functional projection above the verb in the $\mathrm{C}$-domain (see e.g. Thwala 2006), which then entails remnant movement to achieve IAV focus. Such analyses, however, crucially fail to relate the conjoint-disjoint facts or other prosodic effects to IAV focus. For Bemba and Makhuwa, we have seen in (16-17) that IAV focus is accompanied by prosodic effects in the form of conjoint tone in the former case and tonal lowering on the focal element 
in the latter. To complete the picture, let us consider two cases where the conjoint-disjoint distinction is undergoing decay.

In Duala and Basaa (Nurse 2006) only remnants of the conjoint-disjoint forms can be seen, dealt with under a tonal process called Metatony. Metatony is the spread of a high tone to a following tone bearing unit. In the languages concerned here a verb-final vowel becomes high when it is followed by a complement. Disregarding metatony for the moment, the resulting effect is that verbs that are final in their clause are tonally distinguished from those that are not. The focus facts are identical to those seen with conjoint and disjoint forms.

(23) Duala

a. bitó bá-manda
woman 2SM-buy
'women buy'
b. bító bá-mandá mabato
woman 2SM-buy 6basket
'women buy baskets'

(24) Basaa
a. a bínuyul
'he sold'
b. a bínumúl bísel
$(<$ bisel - Metatony)

Thus, in Duala and Basaa where a tonal distinction with respect to a following complement can still be seen, we have IAV focus as opposed to initial focus, pointing to the fact the tonal effects, rather than the conjoint-disjoint distinction which is here under decay, are the indicator of focus (via prosodic structure).

To sum up, focus effects in IAV coincide with the conjoint-disjoint distinction because the distinction is associated with prosodic effects. Languages lacking the distinction show either an absence of focus in IAV position, preferring to have focus on the right or left periphery, or IAV focus only if it is accompanied by extra prosodic effects. We would like to suggest that this correlation points to a prosodic marking of focus and further suggest that this can quite easily be extended to focus in initial and final position since the emphasis is on prosodic phrasing and not the conjoint-disjoint distinction itself. We consider some further evidence for disfavouring a syntactic analysis of focus in the next sub-section before we explore how a prosodic characterisation of focus can be formalised.

\subsubsection{Further evidence against a syntactic focus position in Bantu}

A few other analyses in the Bantu literature also argue against a FocP for Bantu. Marten (2007) proposes an analysis in Dynamic Syntax that does not assign syntactic positions to topic and focus but rather focus interpretation results from an interaction between structural underspecification and context. As already pointed out Buell $(2005,2007)$ assumes an analysis where focus is essentially in-situ with a VP based focus constituent inducing extraposition of all other elements in the VP. Hyman and Polinsky (2007) also argue against a low FocP analysis of the Aghem data illustrating IAV focus as briefly presented in (15) above. Their proposal is that a focus operator in $\mathrm{CP}$ unselectively binds the lowest XP in the clause that then emerges as focused. While these are all viable syntactic options, we opt for an account that also incorporates the associated prosodic effects. Needless to say that the 
prosodic effects could well be effected in one of the ways above, but we leave this to future occasion. We instead focus on the arguments that have been presented against a FocP.

Firstly, for IAV focus, not all constituents that appear in this position are always in focus as would be predicted by the presence of a FocP. As we have seen in Makhuwa and Bemba this may only be in case a conjoint verb form is present. Since the conjoint form is only attested in some tenses per language, in tenses where the distinction is absent constituents in the IAV will not be in focus.

Secondly, the presence of a low FocP requires the verb to precede the focused element in the specifier of FocP above the VP which would require some form of V-to-T movement which, as Buell (2005) argues for Zulu on morpho-syntactic grounds, is poorly motivated.

Thirdly, some of the Bantu languages can focus constituents in multiple positions. As seen in Tumbuka, focus can be both initial or in IAV. Similarly, in Bemba question words may be focused in IAV or in-situ. An analysis postulating a low focus position would then have to further explain how and when movement to this position occurs, and why it appears to be optional in Tumbuka and Bemba. As seen in the Tumbuka case, the different prosodic effects accompanying the attested focus positions directly support a prosodic analysis.

Finally, the availability of multiple constituent questions remains unaccounted for if only one FocP is available. Consider the multiple question forms in (25) below. Zulu data are taken from Buell (2007).

(25) Zulu
a. u-zo-nika bani ini?
2s-FUT-give 1who 9what
'Who will you give what?'
Bemba
b. ú-ká-shìtìshà bààní inshì?
3sg-FUT-buy.CAUS 2who what
'Who will you sell what?'
c. ú-ká-shìtìshà inshì bàànì?
3sg-FUT-buy.CAUS what 2who
'What will you sell to who?'

The Bemba examples show that both the subject and object $w h$-phrases appear after the verb, but that their respective order is free. This seems to indicate that their order is not determined by fixed structural positions, but rather that the syntax of multiple wh-questions is syntactically less restricted, and thus that focus is not tied to a specific designated syntactic projection. We now consider an outline of a prosodic account of focus.

\subsection{A prosodic account of focus}

Returning to the Bemba facts presented in (17), we contend that syntax generates the four different word orders that get mapped into different prosodic structures at PF. Phonological phrasing in Bemba is broadly indicated by a downstepped high usually accompanied by pause. A final phonological phrase is indicated by a final low tone which blocks a high tone doubling rule, that doubles a high tone onto a following vowel, from applying, in the cases where its conditions are met. There is a rising tone on the final vowel of the verb in the conjoint form, so that the absence of a phonological phrase boundary is indicated by the rise. In addition, a segmental effect such as vowel fusion between adjacent constituents is also 
indicative of the absence of a phonological phrase boundary whenever the conditions for this are met (as in example 26c). ${ }^{12}$ Consider the phrasing of the Bemba data in (26) below.

(26) Bemba

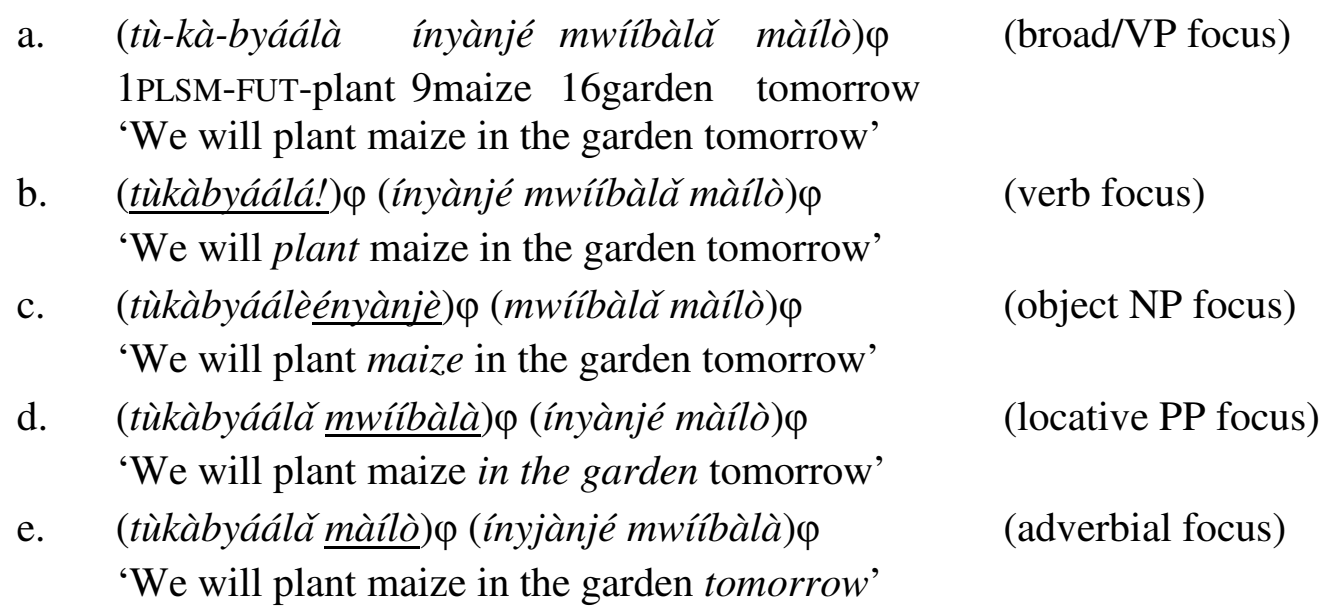

The generalization to be drawn from this phrasing is that the focused constituent occurs at the right edge of a phonological phrase, both for the disjoint form in (26b), where the verb is in focus, and the conjoint forms in (26c-e). Also of significance is the fact that the tonal pattern of (26a), where a broad focus interpretation holds, despite having a conjoint form of the verb differs from (26c-e) tonally showing that there is no phonological phrase break between any of the constituents following the verb. Thus we have a case here where phonological phrasing overrides the conjoint form. ${ }^{13}$ An analysis that identifies the relevant right edge of the phonological phrase is easily formalized using interface and Alignment constraints in Optimality Theory, for example, along the lines of Truckenbrodt (1999), Kula (2007). The salient point is, however, that under a syntax that generates all word orders this prosodic phrasing acts as a filter on what orders are actually possible and what discourse functions occur with them, i.e. identifies which constituent is focused by reference to a phonological phrase edge. Note that we do not actually allude to a notion of prominence as it still remains to be seen what relevance this has for tone as opposed to stress languages. Unlike some of the Bantu languages discussed here, Bemba has no penultimate lengthening that may support any notion of sentence accent. The prosodic effects that highlight or help identify focused constituents are in this sense carried solely by the phonological phrasing. This prosodic phrase edge effect can presumably also be extended to Bantu languages with initial and final focus as seen in Tumbuka and Swahili, respectively, with the difference simply being that in these cases the conjoint-disjoint distinction plays no role in designating the relevant prosodic phrase edges.

We now turn to a case where no change in word order is seen but different constituents within the same sentence can nonetheless be focused.

\subsection{In-situ focus}

In Chichewa, Kanerva (1990: 98) convincingly argues that focus is prosodically marked, and that the focus of different constituents in a sentence coincides with different phonological phrasings. Consider in this respect (27). 
(27) Chichewa
a. (a-na-ményá nyumbá ndí mwáála) $\varphi \quad$ (broad/VP focus) SM-TNS-hit 9house PREP stick
'She/he hit the house with a rock'
b. $\quad($ a-na-méenya $) \varphi($ nyuúmba) $\varphi$ (ndí mwáála) $\varphi$ (verb focus)
'She hit the house with a rock'
c. $\quad(a-n a-m e ́ n y a ́ ~ n y u u ́ m b a) \varphi(n d i ́ ~ m w a ́ a ́ l a) \varphi$
'She hit the house with a rock'
d. (a-na-ményá nyumbá ndí mwáála) $\varphi$ (oblique PP focus)
'She hit the house with a rock'

Phonological phrase boundaries are marked by penultimate lengthening and tonal retraction in Chichewa, as (27) illustrates. Tonal retraction ensures that the end of a phonological phrase does not coincide with a high tone, seen here, for example, in the change of the final tone of anamenya when it is phrase-final. The phonological phrase restructuring reveals that the right edge of a phonological phrase coincides with a focused constituent. We assume that on some principled grounds the leftmost phonological phrase is the relevant one for focus in (27b-c). $(27 \mathrm{a} \& \mathrm{~d})$ which have the same phrasing and same tonal patterns can either involve broad VP focus or focus of the rightmost constituent as in (27d).

The relevance of these data to the current discussion is that under a prosodic analysis prosodic phrasing, just like in the conjoint cases, lends support to in-situ focus so that a focused constituent occurs at the edge of a relevant phonological phrase. In a syntactic analysis on the other hand, these data would be surprising given that Chichewa has illustrated word order flexibility in (14) in which case if a syntactic position was available for focus we would expect the focus to occur there and nowhere else. Under our view prosodic phrasing assigned to the canonical word order at PF would yield the outputs in (27). Thus, these data are best served by an analysis that does not codify focus in syntax.

The foregoing discussion on Bantu has tried to establish that prosody is the most robust cue for focus. Thus, while focus has been related to change in word order and the conjointdisjoint distinction in IAV focus, thereby suggesting a possible (low) focus projection, it has been shown that in all these cases there are prosodic effects that accompany such movement manifested either on the verb or the noun. Furthermore, in languages where the conjointdisjoint distinction is not available, constituents can be focused in initial and final position, with IAV also an option, as long as the relevant prosodic effects are present. It has been shown that the positions for focus are varied, occurring both at the right and left periphery, in clause-medial position (the IAV) and virtually in any position (in-situ). What remains consistent in all these cases are the prosodic effects, albeit manifested differently, that accompany focus. Thus we contend that syntax generates all the possible word orders allowed in a language and prosodic phrasing assigned at PF aids the identification of focus.

Let us now have a look at how these Bantu facts relate to the Romance facts already discussed and how they both conspire to support an interface view of focus.

\section{The Romance-Bantu conspiracy}

Recall that, at the end of section 3, we raised the hypothesis, following Cinque (1993) that syntax alone is capable of accounting for the prosodic, positional and interpretive effects of focused constituents. It was not clear, based on the Romance data alone, how to discard this hypothesis. Based on the evidence from Bantu, it is now possible to readdress this issue. 
The Romance facts showed that there is not a designated functional position for focus. Instead, it was argued that focus tends to appear where the sentence nuclear stress falls, and, whenever, for purely syntactic reasons, this is impossible, repair strategies occur postsyntactically in order for prominence to be assigned. These facts may be summarized as follows:

(a) There is no designated information focus position in Romance;

(b) The fact that information focus appears on the right periphery is a tendency, contingent on facts that have little or nothing to do with discourse, and not a categorical fact;

(c) Focus is always marked prosodically in Romance.

These conclusions are important for the discussion of Bantu languages. The common observation that in Bantu languages, like in Romance, word order appears to be sensitive to discourse functions, calls for a common explanation. If one assumes that, in Romance, this type of sensitivity is to be explained by encoding discourse functions into the syntactic component, this analysis should extend to Bantu. The evidence put forward in section 3 casts doubt on this line of inquiry for Romance, and offers an alternative approach based on an interface view of syntax, prosody and discourse. If this type of interface view holds for Romance, it should also hold for Bantu.

In fact, in section 4, we showed that also in Bantu, there is clear evidence to say that there is no necessary one-to-one correlation between word order and information structure. Crucially, the Bantu facts also show that focus can be indicated by various forms of prosodic effects from which we conclude similarly to Romance that:

(a) There is no designated information focus position in Bantu;

(b) The fact that information focus has been strongly linked to an IAV position is contingent on prosodic effects that may be replicated in other positions and cannot be a categorical fact;

(c) Focus is always related to prosody in Bantu. ${ }^{14}$

This evidence is important for comparing the interface view with an analysis in which position, prosody and interpretation are all accounted for within the syntactic component.

Summing up, the data from Romance made it possible to question the evidence for a one-to-one relationship between word order and information structure, which turned out to be important for the evaluation of the Bantu data. On the other hand, the array of prosodic facts across Bantu languages made it possible to show that prominence assignment cannot be accounted for within syntax in terms of sentence nuclear stress, as has been proposed for Romance.

Together, the evidence coming from the two language groups show that there is a wider variation both on the prosodic and on the syntactic side than one might suppose, but the two sets of evidence conspire in favour of the interface view of focus, according to which focus is not a syntactic primitive, and prosody and discourse act post-syntactically.

\section{Conclusions}

We argued throughout this paper that the distribution of information focus is best understood if focus is not considered a syntactic primitive. The evidence for this claim came from the distribution of focus across Romance and Bantu. It was argued that cross-linguistic and 
language internal variation in the distribution of focus is accounted for if one takes into consideration the structures independently made available by syntax, solely based on syntactic primitives, and their mapping onto prosodic structure.

It is often mentioned that Romance and Bantu have in common the fact that word order reflects information structure. We hope to have provided evidence for a more precise formulation of this similarity. What the two language families have in common is a syntax with a flexibility, due to independent syntactic reasons, that makes it possible to map different word orders onto prosodic structures where the focused constituents are assigned different types of prominence. The two language families however differ in their realisation of 'prominence' with Romance generally opting for coinciding with stress as determined by nuclear stress rules and Bantu opting for prosodic phrasing as the main indicator of the position of focus. Rather than provide evidence for encoding discourse notions in the syntactic component, a closer look at the similarities and differences between the two language families strengthens an interface approach to focus and word order.

1 For the sake of the argument, it is not relevant to know whether heavy NP shift really involves rightward movement or some other type of derivation. Therefore, we are adhering to the most traditional analysis of this construction.

2 An alternative to this analysis is proposed in Samek-Lodovici (2006), who argues that the right-peripheral focused constituents are right-dislocated. For arguments against generalizing this view for all cases of sentencefinal information focus, see Costa (2006).

3 For evidence from acquisition for the last-resort nature of this type of marked stress in focus marking, see Szendroi (2003) and Costa and Szendroi (2006).

4 The issue of prominence is not an easy one in Bantu. Sentential accent has been related to penultimate lengthening attested in most southern Bantu languages but issues of culminativity remain contentious. See Zerbian (2006) and references therein for some discussion.

5 The following less common abbreviations are used in the Bantu data in the remainder of this paper: $\mathrm{D}=$ determiner, DISJ = disjoint form marker, ES = expletive subject, FV = final vowel (in verb forms), LOC = locative, $\mathrm{OM}=$ object marker, $\mathrm{SM}=$ subject marker, $\mathrm{P} 1=$ past of today, $\mathrm{P} 4=$ most remote past and $\mathrm{QM}=$ question marker. Numbers in glosses, unless used for person and number, indicate noun class.

6 A reviewer points out that the sentence in (21c) could be analysed as involving two clauses with yona and the noun it refers to not being in the same clause and in this case yona could be construed as not being a resumptive pronoun. Without being drawn into the long debate on the definition of resumptive pronouns, this would still be problematic for the idea of using the conjoint verb form here, as pronouns can never be focused in object position in Zulu. In this case a conjoint form would be followed by a constituent that cannot be focused hence Buell's point on the lack of consistency in the argument that conjoint forms unambiguously mark following focus.

7 This is reminiscent of Ndayiragidje's (1999) treatment of the conjoint-disjoint forms in Kirundi that is marked by $-r a$ in the disjoint form. He treats $-r a$, which can never signal narrow focus on a following constituent, as an anti-focus marker.

8 For ease of reference we will refer to the tonal marking of the conjoint-disjoint distinction as involving conjoint tone and disjoint tone, respectively.

9 The conjoint-disjoint distinction is attested in Bemba in almost all tenses. The tenses that exclusively use tone are the three progressive pasts, the simple negative past 1 , the present positive and negative, the three progressive futures, the inceptive \& completive immediate future (future 1), the indicative and the subjunctive tenses. The tonal distinction is indicated by a rule that spreads the last structural high on the verb to the final vowel of the disjoint verb form (cf. Sharman 1956, Givón 1975).

10 According to Nurse (2006: 193) this is mainly the Savannah languages of zones D60, M40, M50, M60, P2030, K21, S20-30 and S40-50 of the Bantu language area, following the classification of Guthrie (1967-71).

11 Downing (2006) points out that above all phonological phrasing is the strongest cue for focus in Tumbuka where in-situ focus is also possible and seen to trigger specific prosody. Her argument is based on the fact that culminative sentence accent is not consistently assigned to the focused constituent in Tumbuka.

12 The full characterisation of phonological phrasing and intonation in Bemba are still under investigation but our current state of knowledge is sufficient for the present exposition. 
13 This could be an answer, at least for Bemba, to one of Buell's (2006) concerns that sentences with neutral focus also use the conjoint form; their prosodic phrasing crucially differs from conjoint forms where following constituents are in focus.

${ }^{14}$ One possible counter-example to this is Northern Sotho for which Zerbian (2006) argues that there is no consistent prosodic cue for focus because syntactic requirements override prosodic requirements but the prosodic shape of an utterance remains constant; penultimate lengthening remains final. This scenario is, however, not unexpected in our proposal since we claim that discourse functions do not trigger movement but only act as a filter to structures independently licensed by syntax. Thus, if syntax allows a constituent to occur in clause final position its focus status will coincide with the accentual cues of the clause final position. What is crucially different from Romance, as Zerbian points out, is that no default or last resort strategy is applied to the focus constituent when it does not fall in final position.

\section{References}

Aboh, E.O. 2007. Leftward versus rightward focus: the Kwa-Bantu conspiracy. SOAS Working Paper in Linguistics 15: Bantu in Bloomsbury, Special issue on Bantu Linguistics, 81-104.

Ashton, E.O. 1942. Swahili Grammar. London: Longman.

Baker, M.C. 2003. Agreement, dislocation and partial configurationality. In Formal approaches to function in grammar: In honor of Eloise Jelinek, A. Carnie, H. Harley and M-A. Willie (eds), 107-134. Amsterdam, Philadelphia: John Benjamins.

Belletti, A. 2002. Aspects of the low IP area. In The Structure of IP and CP. The Cartography of Syntactic Structures 2, Luigi Rizzi (ed.), 16-51. Oxford: Oxford University Press.

Bresnan, J. and S.A. Mchombo. 1987. Topic, pronoun, and agreement in Chichewa. Language 63: 741-782.

Buell, Leston. 2007. Evaluating the immediate postverbal position as a focus position in Zulu. Ms. Universiteit Leiden.

Buell, L. 2006. The Zulu conjoint/disjoint verb alternation: Focus or constituency? ZAS Papers in Linguistics 43: Papers in Bantu Grammar and Description, 8-30.

Buell, L. 2005. Issues in Zulu verbal morphosyntax. PhD Dissertation, University of California at Los Angeles.

Cardinaletti, A. 1998. On the deficient/strong opposition in possessive systems. In Possessors, Predicates, and Movement in the Determiner Phrase, A. Alexiadou and C. Wider (eds), 17-53. Amsterdam, Philadelphia: John Benjamins.

Castro, A. and J. Costa. 2003. Weak forms as $\mathrm{X}^{\mathrm{o}}$ : prenominal possessives and preverbal adverbs in Portuguese. In Romance Linguistics: theory and acquisition, A.T. PérezLeroux and Y. Roberge (eds), 95-110. Amsterdam, Philadelphia: John Benjamins.

Cinque, G. 1993. A null theory of phrase and compound stress. Linguistic Inquiry 24: 239298.

Costa, J. 1996. Positions for subjects in European Portuguese. In Proceedings of WCCFL XV, B. Agabayani et al. (eds), 49-63. Stanford: CSLI.

Costa, J. 1998. Word order variation. A constraint-based approach. PhD Dissertation, Leiden University. Holland Academic Graphics.

Costa, J. 2004. Subject positions and interfaces. The case of European Portuguese. Berlin: Mouton de Gruyter.

Costa, J. and M.C. Figueiredo Silva. 2006. On the (in)dependence relation between syntax and pragmatics. In The architecture of focus, V. Molnar and S. Winkler (eds), 83-104. Berlin: Mouton de Gruyter. 
Costa, J. and K. Szendroi 2006. Acquisition of focus marking in European Portuguese: Evidence for a unified approach to focus. In The Acquisition of Syntax in Romance Languages, V. Torrens and L. Escobar (eds), 319-329. Amsterdam, Philadelphia: John Benjamins.

Criessels, D. 1996. Conjunctive and disjunctive verb forms in Setswana. South African Journal of African Languages 16.6: 109-115.

Downing, L.J. 2006. The prosody and syntax of focus in Chitumbuka. ZAS papers in Linguistics 43: Papers in Bantu Grammar and Description, 55-79.

Duarte, M.E. 1995. A Perda do Princípio Evite Pronome no Português do Brasil. PhD Dissertation, Universidade Estadual de Campinas.

Figueiredo Silva, M.C. 1996. A posição do sujeito em português brasileiro - frases finitas e infinitivas. Editora da Unicamp, Campinas, Brazil.

Frota, S. 1998. Prosody and focus in European Portuguese. PhD Dissertation, University of Lisbon.

Frota, S. and M. Vigário. 2002. Efeitos de peso no Português Europeu». In Saberes no Tempo. Homenagem a Maria Henriqueta Costa Campos, M.H. Mateus and C.N. Correia (eds), 315-333. Lisboa: Colibri.

Givón, T. 1975. Focus and scope of assertion. Some Bantu evidence. Studies in African Linguistics 6: 185-205.

Guthrie, M. 1967-71. Comparative Bantu. [Four Volumes]. Farnborough: Gregg.

Horvath, J. 1986. FOCUS in the Theory of Grammar and the Syntax of Hungarian. Dordrecht: Foris.

Hyman, L.M. 1999. The interaction between focus and tone in Bantu. In The Grammar of Focus, G. Rebuschi and L. Tuller (eds), 151-177. Amsterdam, Philadelphia: John Benjamins.

Hyman, L.M. and M. Polinsky. 2007. Focus in Aghem. Unpublished manuscript.

Hyman, L.M. and J.R. Watters. 1984. Auxiliary Focus. Studies in African Linguistics 15: 233-273.

Kanerva, J. 1990. Focus and phrasing in Chichewa phonology. PhD Dissertation, Stanford University.

Krifka, M. 1985. Word order and word order change in Swahili. Kiswahili, Journal of the Institute of Kiswahili Research 52: 13-72.

Kula, N.C. 2007. Effects of phonological phrasing on syntactic structure. The Linguistic Review 24.2: 201-231.

Marten, L. 2007. Focus strategies and the incremental development of semantic representations: Evidence from Bantu. In Focus strategies in African languages: The interaction of focus and grammar in Niger-Congo and Afro-Asiatic, E.O. Aboh, K. Hartmann and M. Zimmermann (eds), 113-135. Berlin, NY: Mouton de Gruyter.

Meeussen, A.E. 1959. Essaie de grammaire Rundi. Annales du Musée Royal du Congo Belge, Série Sciences Humaines 24, Tevuren.

Miguel, M. 2001. Para uma tipologia dos possessivos. Actas do XVII Encontro Nacional da Associação Portuguesa de Linguística, 287-300. Lisbon: APL.

Morimoto, Y. 2000. Discourse configurationality in Bantu morphosyntax. PhD Dissertation, University of Stanford.

Ndayiragije, J. 1999. Checking economy. Linguistic Inquiry 30: 399-444.

Nespor, M. and I. Vogel. 1986. Prosodic Phonology. Foris, Dordrecht.

Nurse, D. 2006. Focus in Bantu. ZAS Papers in Linguistics 43: Papers in Bantu Grammar and Description, 189-207.

Reinhart, T. 1995. Interface Strategies. Ms, UiLOTSIUtrecht University. 
Reinhart, T. 1999. The processing cost of reference-set computation: guess patterns in acquisition. UiLOTS Working Papers in Linguistics.

Roca, F. 2006. Demonstrative systems in Spanish and in Romance: some remarks on diachronic and dialectal variation. Paper presented at Workshop "Romania Nova", Maceió- Brazil.

Sabel, J. and J. Zeller. 2006. Wh-question formation in Nguni. In Selected Proceedings of the 35th Annual Conference on African Linguistics, J. Mugane et al. (eds), 271-283. Somerville, Mass.: Cascadilla.

Sambek-Lodovici, V. 2006. When right dislocation meets the left-periphery. A unified analysis of Italian non-final focus. Lingua 116: 836-873.

Sharman, J.C. 1956. The tabulation of tenses in Bantu languages (Bemba: Northern Rhodesia). Africa 26: 29-46.

Sharman, J.C. and A.E. Meeussen. 1955. The representation of structural tones, with special reference to the tonal behaviour of the verb, in Bemba, Northern Rhodesia. Africa 25: 393-404.

Szendröi, K. 2001. Focus and the syntax-phonology interface. PhD Dissertation, University College London.

Szendröi, K. 2003. Narrow and wide focus interpretation in the acquisition of only sentences. Paper presented at GALA 2003, Utrecht University.

Thwala, N. 2006. Aspects of the syntax of Focus in SiSwati. Ms., SOAS.

Truckenbrodt, H. 1999. On the relation between syntactic phrases and phonological phrases. Linguistic Inquiry 30.2: 219-255.

Van der Wal, J. 2006. The disjoint verb form and an empty immediate after verb position in Makhuwa. ZAS Papers in Linguistics 43: Papers in Bantu Grammar and Description, 233-256.

Watters, J.R. 1979. Focus in Aghem. In Aghem Grammatical Structure [Southern California Occasional Papers in Linguistics No.7.], L.M. Hyman (ed.) Los Angeles: University of California Department of Linguistics.

Zerbian, S. 2006. Expression of information structure in the Bantu language Northern Sotho. PhD Dissertation, Humboldt University, Berlin.

Zubizarreta, M.L. 1998. Focus, prosody and word order. Cambridge: MIT Press. 